\title{
Adrenalectomy reduces neuropeptide $Y$-induced insulin release and NPY receptor expression in the rat ventromedial hypothalamus
}

\author{
Todd Wisialowski, Rachel Parker, Elaine Preston, Amanda Sainsbury, Edward Kraegen, \\ Herbert Herzog, and Gregory Cooney
}

Garvan Institute of Medical Research, 384 Victoria Street, Sydney, Australia

Address correspondence to: Greg Cooney, Garvan Institute of Medical Research, 384 Victoria Street, Darlinghurst, Sydney, NSW 2010, Australia. Phone: 61-2-9295-8209; Fax: 61-2-9295-8201; E-mail: g.cooney@garvan.unsw.edu.au.

Todd Wisialowski and Rachel Parker contributed equally to this work.

Received for publication October 15, 1999, and accepted in revised form March 8, 2000.

Chronic central administration of neuropeptide Y (NPY) causes hyperphagia, hyperinsulinemia, and obesity, a response that is prevented by prior adrenalectomy (ADX) in rats. The basis of NPY's effect and how the acute responses to this peptide are affected by ADX remain unknown. This study investigates the role of glucocorticoids in acute NPY-stimulated food intake, acute NPY-induced insulin release, and hypothalamic NPY-receptor mRNA expression levels. NPYinduced food intake was similar in ADX and control rats after acute intracerebroventricular injection of NPY. Injection of NPY caused a significant increase in plasma insulin in control rats, but this effect was completely absent in ADX rats in which basal plasma insulin levels were also lower than controls. In addition, ADX significantly reduced the number of neurons expressing NPY receptor $Y_{1}$ and $Y_{5}$ mRNAs in the ventromedial hypothalamus $(V M H)$, without affecting $Y_{1-}$ or $\mathrm{Y}_{5}$-mRNA expression in the paraventricular hypothalamus or the arcuate nucleus. These data indicate that glucocorticoids are necessary for acute NPY-mediated insulin release and suggest that the mechanisms involve glucocorticoid regulation of $Y_{1}$ and $Y_{5}$ receptors specifically within the VMH nucleus.

J. Clin. Invest. 105:1253-1259 (2000).

\section{Introduction}

Obesity, which is an important risk factor for serious chronic illnesses such as insulin resistance, type 2 diabetes, and heart disease is caused by an imbalance between energy intake and energy expenditure. There are numerous factors influencing whole-body energy balance, including neural and hormonal signals, which, when altered could result in obesity. It is becoming increasingly evident that the central nervous system, particularly the hypothalamus, plays a critical role in integrating these signals to regulate energy balance and that neuropeptide Y (NPY) is an important neuromodulator in this system $(1,2)$.

NPY is widely distributed throughout the brain (3). However, most of the metabolic actions of NPY appear to be mediated through defined hypothalamic nuclei, including the arcuate nucleus (Arc) where numerous NPY-containing neurons originate, the paraventricular nucleus (PVN), where many NPYcontaining arcuate neuron terminals and NPY-binding sites are located, and the ventromedial hypothalamic (VMH) nucleus, which has been referred to as "the satiety center" $(3,4)$. NPY is the most potent orexigenic agent known $(5,6)$ and can also cause changes in circulating hormone levels (7). Chronic intracerebroventricular (icv) administration of NPY results in hyperphagia, hyperinsulinemia, insulin resistance, and obesity (8-10). Lesions of the VMH in rodents also cause multiple changes in metabolic status, including hyperphagia, hyperglycemia, and hyperinsulinemia (11). Interestingly, injection of NPY directly into the VMH significantly increases food intake (12), and NPY-induced feeding is enhanced in VMH-lesioned rats (13). These data suggest the VMH may also be a site of action for NPY in the development of obesity; however, the mechanisms by which NPY is involved in each aspect of central energy regulation remain to be defined.

Much research has focused on which of the 5 NPYreceptor subtypes cloned so far $\left(\mathrm{Y}_{1}, \mathrm{Y}_{2}, \mathrm{Y}_{4}, \mathrm{Y}_{5}\right.$, and the y6) (14) might mediate the potent NPY-induced feeding response. Several lines of evidence point to the $\mathrm{Y}_{1}$ - and/or $\mathrm{Y}_{5}$-receptor subtypes being the most likely candidates for such an action (15-19). In addition, our previous studies investigating the mRNA expression of all known $\mathrm{Y}$ receptors in the rat brain also show clearly that both $\mathrm{Y}_{1}$ - and $\mathrm{Y}_{5}$-receptor subtype mRNAs are expressed in areas pivotal in regulating energy balance (20).

Glucocorticoid hormones play a critical role in energy balance and also appear to mediate at least some of their actions through the central NPY axis 


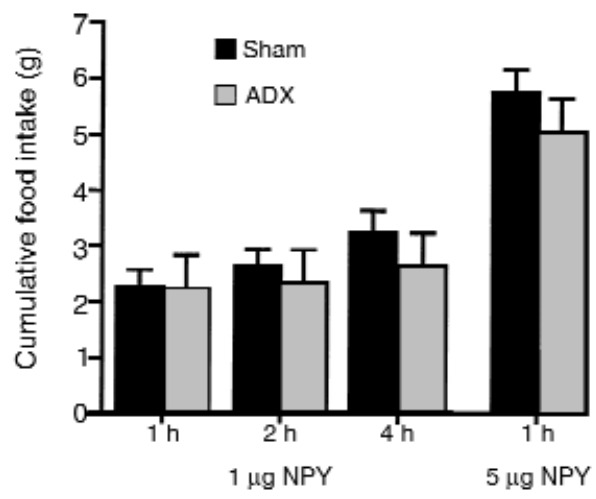

Figure 1

The effect of adrenalectomy on NPY-induced food intake in rats. Rats received an acute injection of $1 \mu \mathrm{g} \mathrm{NPY} \mathrm{(icv),} \mathrm{and} \mathrm{cumulative}$ food intake was monitored over the next 4 hours. In a second set of experiments NPY $(5 \mu \mathrm{g})$ was injected icv and blood sampled for 2 hours without food being available. After 2 hours, food was presented to the rats and food intake monitored over the subsequent hour. Results are expressed as the mean \pm SE. Black bars represent sham-operated NPY-injected rats $(n=12)$, and gray bars represent ADX NPY-injected rats $(n=7)$.

(21). In rats, excessive corticosterone promotes body fat gain (22) and hyperinsulinemia (23) and also increases NPY synthesis and $\mathrm{Y}_{1}$-receptor mRNA expression, at least within the $\operatorname{Arc}(24,25)$. Conversely, removal of glucocorticoids by adrenalectomy $(\mathrm{ADX})$ reduces hyperphagia and body weight of obese $(f a / f a)$ rats (26), abolishes obesity induced by VMH lesions (27), and prevents obesity induced by chronic central NPY infusion in normal rats (28). However, it has been reported that $\mathrm{ADX}$ does not alter $\mathrm{Y}_{1^{-}}$ receptor mRNA expression in the Arc (24). Glucocorticoid-receptor immunoreactivity is found within the rat central nervous system, including the Arc, VMH, and PVN (29). Many of these receptors are expressed at the nucleus of NPY-containing, endocrine-related neurons and coexist in regions containing high NPYreceptor density (30).

Taken together, these observations indicate that glucocorticoids have a regulatory role in long-term central NPY signaling. However, it is not known what regulatory role, if any, glucocorticoid hormones have in the effects of acute, central administration of NPY and how these actions relate to NPY-receptor expression. Therefore, we have examined the effects of ADX on acute icv NPY-stimulated food intake and insulin release in rats. Furthermore, we have analysed the effects of $A D X$ on $Y_{1}$ - and $Y_{5}$-receptor mRNA expression within specific brain regions reported to regulate food intake and energy balance (Arc, PVN, and $\mathrm{VMH}$ ), using subtype-specific riboprobes and employing a uniform technique of in situ hybridization histochemistry. The results show that ADX reduces basal plasma insulin levels, abolishes NPYinduced insulin release, and significantly decreases $\mathrm{Y}_{1}$ - and $\mathrm{Y}_{5}$-receptor mRNA expression selectively within the VMH. These data suggest that glucocorticoids regulate NPY-induced insulin release and NPY signaling within the VMH of the hypothalamus.

\section{Methods}

Animals and surgical procedures

All procedures were approved by the Animal Experimentation Ethics Committee (Garvan Institute and St. Vincent's Hospital, Sydney, Australia) and were in accordance with the National Health and Medical Research Council of Australia (NHMRC) guidelines on animal experimentation.

Male Wistar rats (275-350 g) were housed under standard lighting conditions (6:00 am to $6: 00 \mathrm{pm})$ with chow and water available ad libitum. Under ketamine (60 mg/kg; Parke Davis, Caringbah, Australia) and xylazine $(10 \mathrm{mg} / \mathrm{kg}$; Bayer AG, Leverkusen, Switzerland) anesthesia, a 22-gauge guide cannula (Plastics One, Roanoke, Virginia, USA) was positioned and fixed in the right lateral ventricle (icv) using a stereotaxic surgical table and coordinates obtained from a rat brain atlas (31). A cannula for blood sampling was inserted into the jugular vein and routed out through a small incision on the back between the shoulders. It was plugged with polyvinylpyrrolidone (PVP) in heparin saline to prevent clotting and leaking. The rats were allowed to recover for at least 7 days. After this recovery period, rats were tested for correct cannula placement by a 4-hour feeding study after

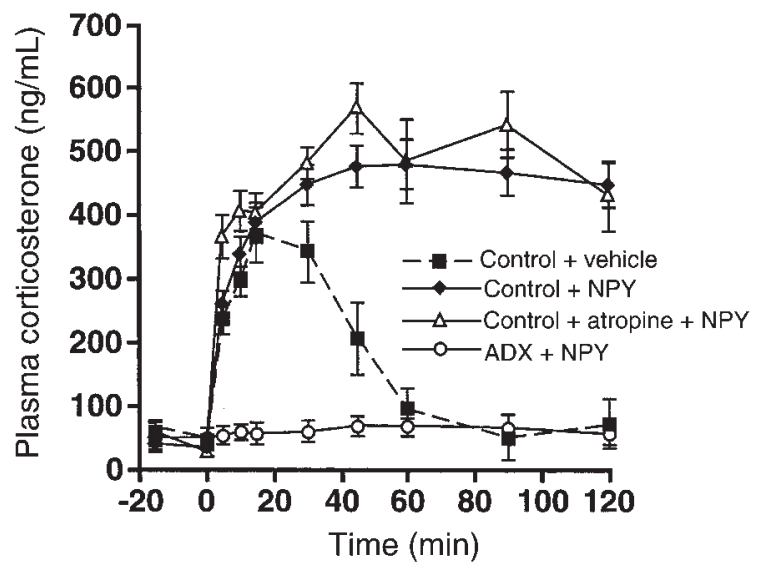

Figure 2

Plasma corticosterone concentration after acute NPY injection in normal, atropine-treated, and ADX rats. Plasma corticosterone was measured after icv injection of vehicle or NPY $(5 \mu \mathrm{g})$ in normal, atropine-treated ( $1 \mathrm{mg} / \mathrm{kg}$ intravenously) or ADX rats as described in Methods. Results are shown as the mean \pm SE for 5-7 animals per group. Filled squares represent vehicle-injected rats, filled diamonds represent NPY-injected rats, open triangles represent atropine-treated NPY-injected rats, and open circles represent NPYinjected ADX rats. NPY-injected normal rats and NPY-injected atropine-treated rats had significantly higher corticosterone release $(P<0.0001)$ than vehicle-injected normal rats or NPY-injected ADX rats as assessed by repeated measures ANOVA. 
acute icv NPY injection $(5 \mu \mathrm{g})$. A subgroup of the rats with significant food consumption after icv NPY were reanesthetized, and both adrenal glands were surgically removed (ADX). Rats were given $0.9 \%$ saline in their drinking water to maintain electrolyte balance. Rats were handled and monitored daily to minimize any stress during the experiments, which were performed 8-10 days after the second surgical procedure. ADX rats maintained normal food intake and body weight gain after the surgical procedures and were healthy in appearance and behavior.

\section{Injection of compounds}

NPY (Auspep Pty. Ltd., Melbourne, Australia) was dissolved in $0.9 \%$ saline and injected as $5-\mu \mathrm{g}$ and 1 $\mu \mathrm{g}$ doses in a volume of $5 \mu \mathrm{L}$. Icv injections were performed using a 28-gauge injection cannula (Plastics One) connected to a Hamilton-1801RN $10-\mu \mathrm{L}$ syringe through Silastic tubing. Atropine methyl nitrate (Sigma Chemical Co., St. Louis, Missouri, USA) was given as a bolus ( $1 \mathrm{mg} / \mathrm{kg})$ through the jugular catheter 20 minutes before the icv administration of NPY.

\section{Experimental design}

Measurement of food intake. On the morning of the experiment, rats were placed in individual cages with access to drinking water and allowed to acclimatize for about 1 hour. ADX and control rats were given an icv injection of NPY $(1 \mu \mathrm{g})$ and returned to their cages with ad libitum access to food and water. Food intake was measured at 1,2, and 4 hours after injection. Other groups of sham and ADX rats were treated with vehicle (icv $5 \mu \mathrm{L} 0.9 \%$ saline) for comparison.

Blood sampling procedure. Rats were placed in individual cages with access to water, and Silastic tubing was connected to the in-dwelling jugular cannula for blood sampling. After a 60- to 90-minute acclimatization period, two basal blood samples were taken approximately 15 minutes apart. Rats were removed from the cages and injected with NPY $(5 \mu \mathrm{g} / 5 \mu \mathrm{L}$ over 30 seconds) and returned to their cages for blood sampling. Control experiments were per- formed with icv injection of vehicle (5 $\mu \mathrm{L} 0.9 \%$ saline). Two additional groups of animals were given a bolus injection of a muscarinic receptor blocker (1 $\mathrm{mg} / \mathrm{kg}$ atropine methyl nitrate ) 20 minutes before icv NPY or saline injection to assess the role of the parasympathetic nervous system in any hormonal responses to the administration of NPY. Blood samples $(300 \mu \mathrm{L})$ were collected at regular intervals for 2 hours after icv injection. The plasma was separated by centrifugation, placed on ice, and plasma glucose determined before storing at $-20^{\circ} \mathrm{C}$ for further assays. The red cells were resuspended in heparin saline and returned to each rat. Food was presented 2 hours after icv injection of NPY or vehicle, and intake was measured over the next hour to confirm efficacy of the NPY injection.

Plasma measurements. Plasma glucose was measured using a YSI 2300 STAT Plus Glucose \& L-Lactate Analyzer (Yellow Springs Instrument Co. Inc., Yellow Springs, Colorado, USA). Plasma insulin and leptin were measured using radioimmunoassay kits supplied by Linco Research, Inc. (St. Charles, Missouri, USA). Plasma corticosterone was measured using a ImmuChem Double Antibody Corticosterone RIA Kit for rats and mice (ICN Biomedicals Inc., Costa Mesa, California, USA).

In situ hybridization histochemistry

In situ hybridization was essentially carried out as described previously, at a hybridization temperature of $50^{\circ} \mathrm{C}$, using $200 \mathrm{ng} / \mathrm{mL}$ each of ${ }^{11}$ digoxigeninUTP-labeled riboprobe (20).

Data analysis. Regions containing positive hybridization (dark brown/indigo color precipitate deposit showing a halo pattern in the cytoplasm surrounding a clearly visible nucleus) were identified and mapped with the aid of a rat brain atlas (31). The numbers of positively expressing cell bodies were counted within the right and left PVN and Arc and over a standard area for each VMH $(n=8$ brain sections each from $3 \mathrm{ADX}$ and 3 control rats). No detailed distinctions were made between subdivisions within these nuclei. The levels of receptor-sub-

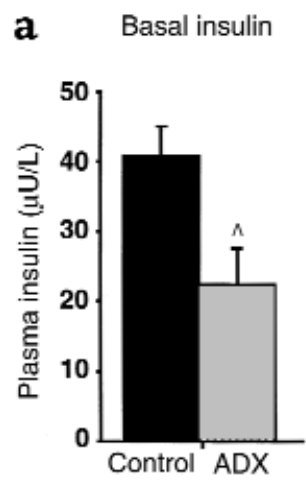

\section{b}

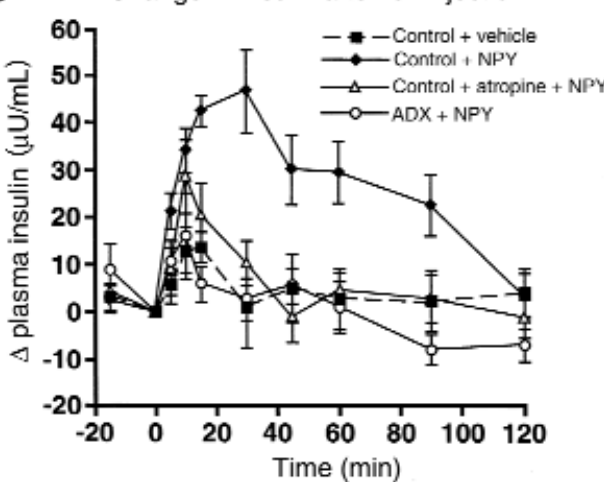

\section{Figure 3}

Plasma insulin concentration after acute NPY injection in normal, atropine-treated, and ADX rats. Plasma insulin was measured in the same plasma samples as those used to generate Figure 2. Results are shown as the mean \pm SE for 5-7 animals per group. (a) The effect of ADX on basal plasma insulin $\left({ }^{A} P<0.05\right)$. (b) The change in plasma insulin after icv infusion of vehicle or NPY. Filled squares represent vehicleinfused rats, filled diamonds represent NPY-injected rats, open triangles represent atropine-treated NPY-injected rats, and open circles represent NPY-injected ADX rats. NPYinjected normal rats had significantly higher insulin release $(P<0.0001)$ than vehicle-injected normal rats, NPY-injected atropine-treated normal rats, or NPY-injected ADX rats as assessed by repeated measures ANOVA. 

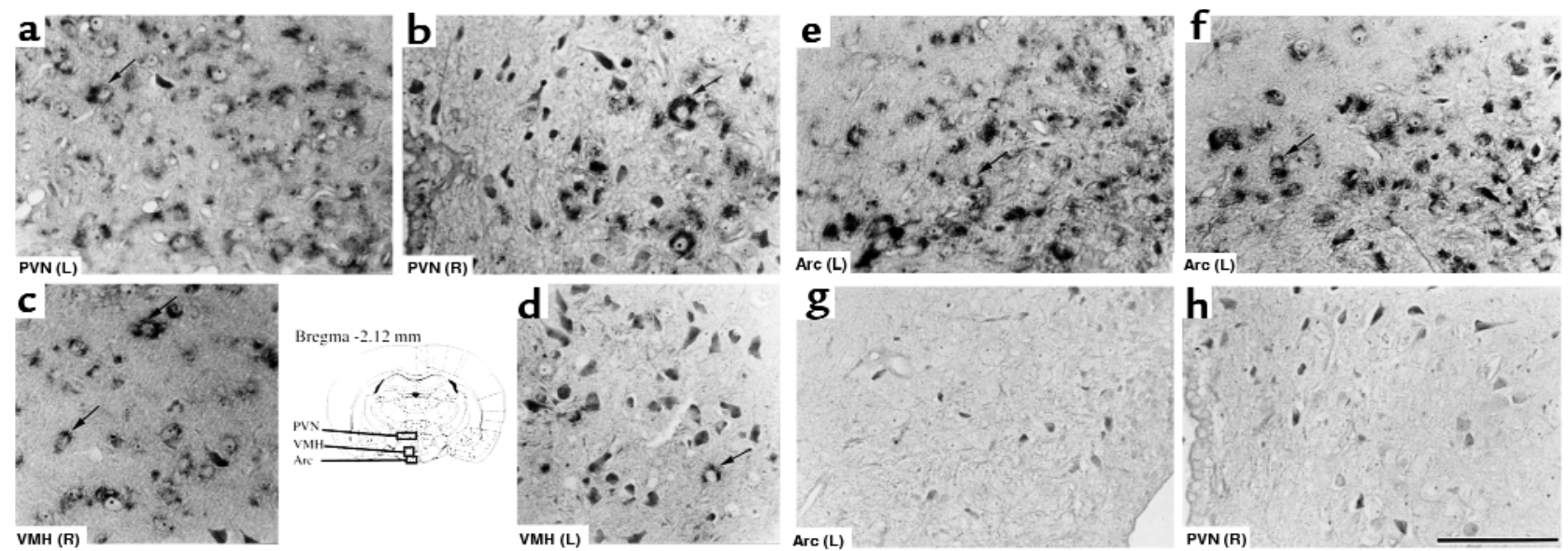

Figure 4

Photomicrograph of expression of $Y_{1}$-receptor mRNA within hypothalamic nuclei of normal and ADX rats. Specific mRNA was detected by in situ hybridization of serial sections of sham-operated and ADX rats as described in Methods. (a, $\mathbf{c}$, and $\mathbf{e})$ PVN, VMH, and Arc of normal brains. ( $b, \mathbf{d}$, and $\mathbf{f}$ ) PVN, VMH, and Arc of ADX rats. ( $\mathbf{g}$ and $\mathbf{h}$ ) Sense controls. The inset shows the schematic of the regions photographed. Positive signals are defined as a color precipitate diffused around the nucleus (arrows). Scale bar $=100 \mu \mathrm{m}$.

type mRNA signal detected within these specific hypothalamic areas were compared in control and ADX rat brain sections obtained under the same assay conditions, and high-power photomicrographs were taken. Adjacent sections were counterstained with hematoxylin/eosin to confirm morphological identification of these hypothalamic areas.

Statistical analysis. Data are expressed as mean $\pm \mathrm{SE}$, either as raw data or change from baseline conditions. Repeated measures ANOVA with relevant post-hoc analysis was used to determine significant differences between treatment groups, and unpaired $t$ tests were used to determine the significant difference for the in situ hybridization results. A probability less than 0.05 was considered to be statistically different.

\section{Results}

Effects of ADX on NPY-induced feeding. An acute icv injection of NPY $(1 \mu \mathrm{g})$ stimulated food intake to a similar degree in both ADX and control rats at 1,2, and 4 hours after NPY injection (Figure 1). When food was presented to animals 2 hours after administration of $5 \mu \mathrm{g}$ NPY and blood sampling, the food intake of control and ADX rats was also not significantly different (Figure 1). Both sham and ADX animals injected with saline vehicle icv consumed less than $1 \mathrm{~g}$ of food over the 4-hour period, and there was no effect of ADX on the spontaneous overnight food intake of the rats (data not shown).

Effect of ADX on NPY-induced changes in plasma hormones in the absence offeeding. In control rats without access to food during the experiment, acute icv injection of vehicle ( $5 \mu \mathrm{L} 0.9 \%$ saline) caused a significant rise in plasma corticosterone, which returned to basal levels after 60 minutes (Figure 2). This response was similar if the rats were handled without any icv injection (data not shown) and occurred despite the fact that all rats were handled on a daily basis to reduce stress. Injection of $5 \mu \mathrm{g}$ NPY (icv) produced a further increase in plasma corticosterone levels compared with vehicle injection $(P<0.05)$, and corticosterone remained elevated for at least 2 hours after NPY injection (Figure 2). Blockade of muscarinic receptors with atropine had no effect on the NPY-induced increase in corticosterone levels, indicating that the effect of icv NPY administration on corticosterone release was not mediated through the parasympathetic nervous system and the vagus nerve (Figure 2). As expected, in $\mathrm{ADX}$ rats there was no increase in corticosterone levels after acute icv injection of NPY.

Acute icv injection of NPY $(5 \mu \mathrm{g})$ also caused a significant increase in plasma insulin levels compared with vehicle $(P<0.05)$, and insulin remained elevated for 90 minutes (Figure 3). Treatment of normal rats with an intravenous bolus of a muscarinic receptor blocker (atropine) 20 minutes before icv NPY administration reduced the effect of NPY injection on insulin release to a level that was not significantly different from that of vehicle administration. Atropine had no significant effect in vehicle-injected rats. This indicates that the effect of central NPY administration on insulin release is mediated by an increase in parasympathetic nervous system activity through vagal innervation of the pancreas. ADX rats had significantly reduced basal plasma insulin levels compared with controls $(22.3 \pm 4.7$ and $41.3 \pm 4.7$ $\mu \mathrm{U} / \mathrm{mL}$, respectively; $P<0.05$, see Figure $3 \mathrm{a}$ ), and there was no significant increase above basal levels after acute NPY injection in ADX rats (Figure 3). The differences in insulin were not due to differences in plasma glucose levels, which were similar in the control and ADX rats and did not change after acute NPY injection ( $P<0.42$; data not shown). Circulating leptin was significantly decreased in ADX rats com- 

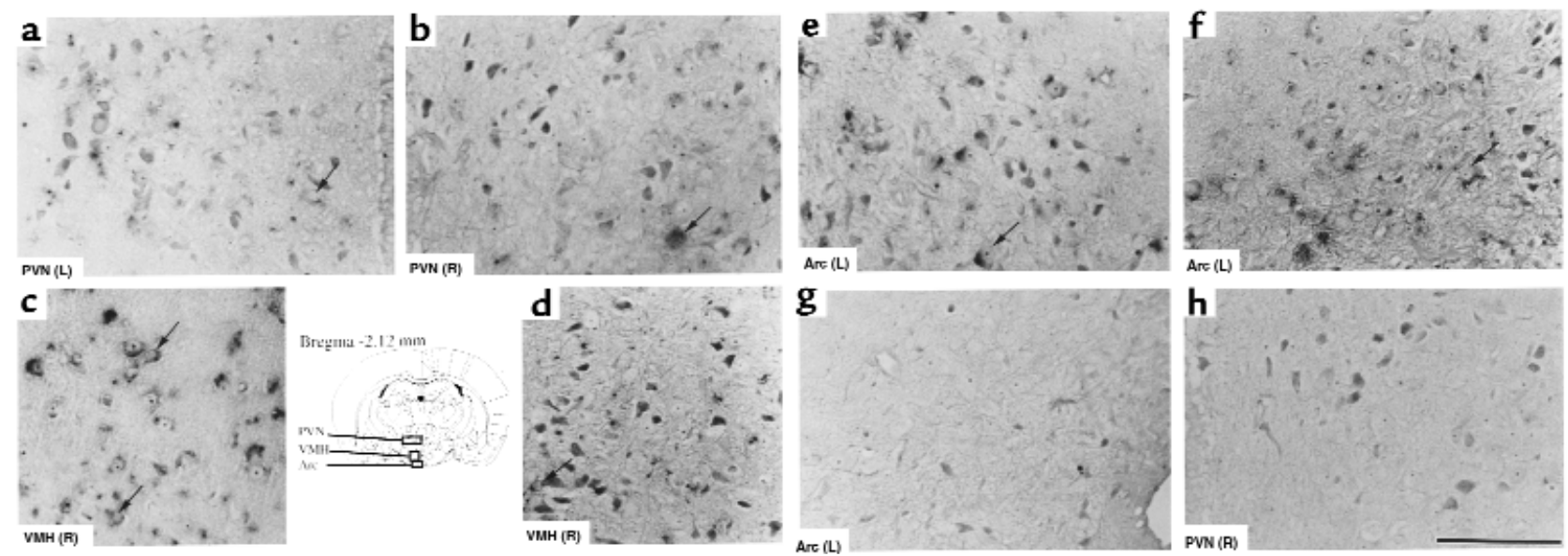

\title{
Figure 5
}

Photomicrograph of expression of $\mathrm{Y}_{5}$-receptor mRNA within hypothalamic nuclei of normal and ADX rats. Specific mRNA was detected by in situ hybridization of serial sections of sham-operated and ADX rats as described in Methods. (a, c, and e) PVN, VMH, and Arc of normal brains. (b, d, and $\mathbf{f})$ PVN, VMH, and Arc of ADX rats. ( $\mathbf{g}$ and $\mathbf{h}$ ) Sense controls. The inset shows the schematic of the regions photographed. Positive signals are defined as a color precipitate diffused around the nucleus (arrows). Scale bar $=100 \mu \mathrm{m}$.

pared with controls $(1.6 \pm 0.2$ and $3.6 \pm 0.4 \mathrm{ng} / \mathrm{mL}$, respectively) but there was no change in these levels with acute injection of NPY (data not shown).

$Y_{1}$-and $Y_{5}$-receptor $m R N A$ expression. Nonradioactive in situ hybridization employing rat $\mathrm{Y}_{1-}$ and $\mathrm{Y}_{5}$-specific riboprobes was used to determine possible changes in Y-receptor expression after ADX. No cross-reactivity occurred when each receptor-specific riboprobe was hybridized under conditions identical to those used for in situ hybridization against vector constructs for each of the other known Y-receptor subtypes. This result was not surprising given the very low sequence identity of the different Y-receptor subtypes (14). Furthermore, neither of the corresponding sense riboprobes used under the same assay conditions showed specific hybridization (Figures 4, $\mathrm{g}$ and $\mathrm{h}$, and Figure 5, $\mathrm{g}$ and $\mathrm{h}$ ).

In the PVN, VMH, and Arc of control rats there was approximately twice the number of neurons expressing $\mathrm{Y}_{1}$-receptor $\mathrm{mRNA}$ as those expressing $\mathrm{Y}_{5}$-receptor mRNA (Figures 4, 5, and 6). These values confirm those reported previously by our group using similar hybridization techniques (20) and are comparable with other published data, at least for $\mathrm{Y}_{1}$ mRNA expression levels within normal Arc using a different technique of in situ hybridization (32). Bilateral ADX caused a significant reduction in the number of neurons expressing $\mathrm{Y}_{1^{-}}$(by up to $80 \% ; P<0.01$ ) and $\mathrm{Y}_{5^{-}}$(by 50\%; $P<0.01$ ) receptor mRNA within the VMH (Figures $4 \mathrm{~d}, 5 \mathrm{~d}$, and 6 ). However, ADX did not significantly change the numbers of neurons expressing $\mathrm{Y}_{1}$ and/or $\mathrm{Y}_{5}$-receptor mRNA within the PVN or the Arc.

\section{Discussion}

Chronic icv infusion of NPY induces hyperphagia, hyperinsulinemia, and insulin resistance in rats, and these effects are blocked by previous ADX (28). In the current study we demonstrate that ADX also abolishes the insulin release caused by an acute icv injection of NPY and that this is associated with significantly reduced $\mathrm{Y}_{1^{-}}$and $\mathrm{Y}_{5}$-receptor mRNA expression specifically within the VMH. These experiments imply that glucocorticoids are necessary for icv NPY to stimulate insulin release and suggest that glucocorticoids manifest this regulatory role through alterations in $\mathrm{Y}_{1^{-}}$and $\mathrm{Y}_{5}$-receptor expression in the $\mathrm{VMH}$.
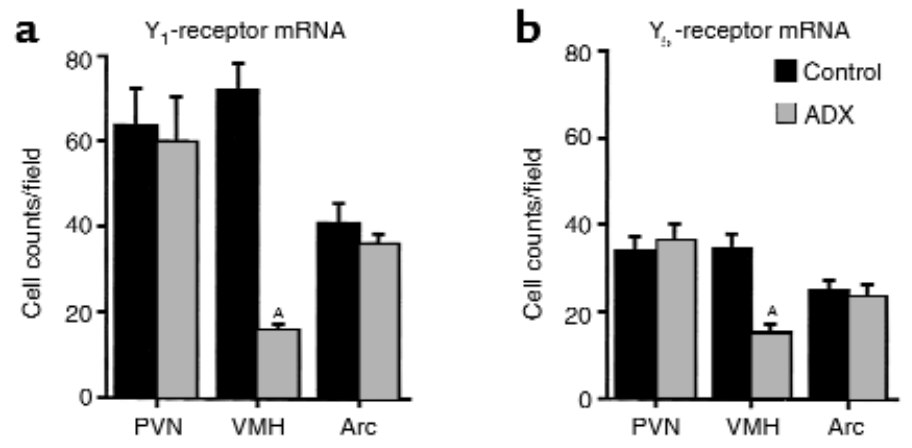

\begin{abstract}
Figure 6
Quantification of expression of $\mathrm{Y}_{1}$ - and $\mathrm{Y}_{5}$-receptor mRNA within hypothalamic nuclei. The number of cell bodies staining for $Y_{1}$ - and $Y_{5}$-receptor mRNA was quantified as described in Methods. (a) The number of cells showing hybridization for $\mathrm{Y}_{1}$-receptor mRNA in the PVN, the VMH, and the Arc. (b) The number of cells showing hybridization for $\mathrm{Y}_{5}$ mRNA in the same regions of the hypothalamus. Plotted data represent the mean \pm SE for determinations from 3 separate control and ADX animals. AP $<0.001$, unpaired $t$-test.
\end{abstract}

Hypothalamic region 
Interestingly, in this study ADX rats showed no significant alteration in the feeding response to acute NPY injection. Therefore, it was not surprising that these ADX rats also showed no change in expression of $Y_{1}$ and $\mathrm{Y}_{5}$-receptor mRNA (the proposed NPY feeding receptors) within the PVN. There are contradictory reports in the literature regarding the effects of ADX on NPY-induced food intake. Some studies show that food intake measured 1 hour after direct NPY administration into the PVN was partially attenuated by ADX and was restored by corticosterone treatment $(33,34)$. However, in agreement with our results, others report that ADX had no significant effect on food intake in rats during 2 hours of NPY infusion (35) or 2 hours after acute icv NPY administration (36).

The fact that we found no change in the expression of $Y_{1}$ - and $Y_{5}$-receptor mRNA levels in the PVN and Arc indicates that glucocorticoids are not essential for basal regulation of $Y_{1}$ - and $Y_{5}$-receptor $m R N A s$ within these areas. Our findings are in agreement with and further extend previous studies, showing that glucocorticoids are not essential for the regulation of $\mathrm{Y}_{1}$-receptor mRNA in the Arc (24), and that ADX does not alter ${ }^{125} \mathrm{I}$ PYY-specific binding in the Arc or PVN (25).

The current study, we believe, is the first to demonstrate that $\mathrm{ADX}$ alters $\mathrm{Y}_{1}$ - and $\mathrm{Y}_{5}$-receptor $\mathrm{mRNA}$ expression in the $\mathrm{VMH}$. A role for the $\mathrm{VMH}$ in insulin secretion and adrenocortical regulation has been proposed previously (37), but the mechanisms whereby glucocorticoids may mediate the effects we observe on $\mathrm{Y}_{1}$ - and $\mathrm{Y}_{5}$-receptor mRNAs in the VMH are unknown. These effects could be a direct action of glucocorticoids as glucocorticoid-receptor immunoreactivity is widely distributed throughout the rat forebrain, including the $\mathrm{VMH}$ (29). In addition, the $\mathrm{Y}_{1}$-receptor gene is known to contain a putative glucocorticoid response element (38), and it has been reported that supplemental corticosterone treatment to ADX rats increases NPY receptor-binding sites and $\mathrm{Y}_{1}$-receptor mRNA levels within discrete hypothalamic nuclei (24, 25). It should be noted that other response elements may also be involved in tissue-specific Y-receptor regulation (38) and that changes in mRNA levels do not necessarily equate to changes in the amount of receptor protein (39). However, these findings do link ADX-induced effects on Y-receptor expression in the $\mathrm{VMH}$ with alterations in the insulinemic response to exogenous NPY, indicating that these mRNA changes may indeed be of physiological significance. Studies involving replacement of glucocorticoids and restoration of $Y_{1}$-and $Y_{5}$-receptor expression and NPY-induced insulin release would be necessary to establish more directly the role of corticosterone in the observed effects of ADX. However, such experiments can provide differing results, depending on the type and route of glucocorticoid replacement $(24,40)$. A recent study has shown that icv infusion of dexamethasone for 3 days increases insulin levels in normal rats, which provides some evidence for a central effect of glucocorticoids in controlling insulin release possibly through altering NPY-regulated pathways (40).
It is also possible that glucocorticoids act by regulating levels of corticotropin-releasing hormone (CRH), which has been reported to significantly decrease food intake (41), insulinemia (42), and inhibit the synthesis and release of NPY (43). Although changes in CRH action have not been linked to changes in $\mathrm{Y}_{1}$ - and $\mathrm{Y}_{5}$-receptor mRNA, the reduction in NPY action following ADX may be a result of increased CRH activity as well as decreased corticosterone levels. Recently, it has been shown that ADX results in a similar, although not so marked, reduction in type $2 \mathrm{CRH}$-receptor (CRHR2) mRNA levels within the VMH, without any change in levels within the PVN (44). It is noteworthy that the specific reduction in $\mathrm{VMH}$ CRHR2 mRNA in these rats was also associated with a decreased body weight and decreased basal plasma insulin and leptin levels. However, the exact roles of these receptors within the $\mathrm{VMH}$ are far from understood.

Enhanced NPY expression in the VMH is associated with the obesity syndrome (45). Furthermore, NPY has been shown to directly inhibit over one fifth of spontaneously active rat VMH neurons, and this inhibition is potentiated by overfeeding (46). Therefore, the mechanism by which acute icv NPY stimulates insulin release in the absence of feeding may be by inhibiting the spontaneous activity of the VMH through $Y_{1}$ and $\mathrm{Y}_{5}$ receptors. A reduction of these receptors with ADX would then reduce the ability of NPY to inhibit VMH neurons. In agreement with others, we found that acute icv NPY administration had no affect on plasma glucose levels, indicating that NPY-induced insulin release is not simply a secondary response to changes in peripheral glucose (47). By associating the decreased basal insulin levels and lack of insulin release in response to NPY injection in ADX rats with downregulation of $\mathrm{Y}_{1}$-and $\mathrm{Y}_{5}$-receptor mRNA in the $\mathrm{VMH}$, our study highlights a role for $\mathrm{Y}_{1}$-and $\mathrm{Y}_{5}$-receptors in the VMH in the etiology of NPY-induced hyperinsulinemia, insulin resistance, and obesity.

In summary, acute NPY-stimulated insulin release was blocked by ADX, an effect that coincided with selective reduction in $\mathrm{Y}_{1^{-}}$and $\mathrm{Y}_{5}$-receptor mRNAexpressing neurons in the $\mathrm{VMH}$. These data suggest that glucocorticoids are necessary for acute NPY-stimulated insulin release and indicates that the mechanisms of action for this effect of NPY involves the $\mathrm{Y}_{1}$ and $\mathrm{Y}_{5}$ receptors in the $\mathrm{VMH}$.

\section{Acknowledgments}

This study was made possible by Research Grants from the National Health and Medical Research Council of Australia. The authors gratefully acknowledge the expert technical assistance of Donna Wilks and all the staff members of the Biological Testing Facility at the Garvan Institute of Medical Research.

\footnotetext{
1. Kalra, S.P., et al. 1999. Interacting appetite-regulating pathways in the hypothalamic regulation of body weight. Endocr. Rev. 20:68-100.

2. Inui, A. 1999. Feeding and body-weight regulation by hypothalamic neuropeptides-mediation of the actions of leptin. Trends Neurosci. 22:62-67. 3. De Quidt, M.E., and Emson, P.C. 1986. Distribution of neuropeptide Ylike immunoreactivity in the rat central nervous system II. Immunohis-
} 
tological analysis. Neuroscience. 18:545-618.

4. Dumont, Y., Fournier, A., St-Pierre, S., and Quirion, R. 1993. Comparative characterization and autoradiographic distribution of neuropeptide Y receptor subtypes in the rat brain. J. Neurosci. 13:73-86.

5. Clark, J.T., Kalra, P.S., Crowley, W.R., and Kalra, S.P. 1984. Neuropeptide $\mathrm{Y}$ and human pancreatic polypeptide stimulate feeding behaviour in rats. Endocrinology. 115:427-429.

6. Stanley, B.G., and Leibowitz, S.F. 1985. Neuropeptide Y injected in the paraventricular hypothalamus: a powerful stimulant of feeding behavior. Proc. Natl. Acad. Sci. USA. 82:3940-3943.

7. Marks, J.L., and Waite, K. 1996. Some acute effects of intracerebroventricular neuropeptide $Y$ on insulin secretion and glucose metabolism in the rat. J. Neuroendocrinol. 8:507-513.

8. Stanley, B.G., Kyrkouli, S.E., Lampert, S., and Leibowitz, S.F. 1986. Neuropeptide $Y$ chronically injected into the hypothalamus: a powerful neurochemical inducer of hyperphagia and obesity. Peptides. 7:1189-1192.

9. Vettor, R., Zarjevski, N., Cusin, I., Rohner-Jeanrenaud, F., and Jeanrenaud, B. 1994. Induction and reversibility of an obesity syndrome by intracerebroventricular neuropeptide $\mathrm{Y}$ administration to normal rats. Diabetologia. 37:1202-1208.

10. Zarjevski, N., Cusin, I., Vettor, R., Rohner-Jeanrenaud, F., and Jeanrenaud, B. 1993. Chronic intracerebroventricular neuropeptide-Y administration to normal rats mimics hormonal and metabolic changes of obesity. Endocrinology. 133:1753-1758.

11. Penicaud, L., et al. 1989. Development of VMH obesity: in vivo insulin secretion and tissue insulin sensitivity. Am. J. Physiol. 257:E255-E260.

12. Stanley, B.G., Chin, A.S., and Leibowitz, S.F. 1985 . Feeding and drinking elicited by central injection of neuropeptide Y: evidence for a hypothalamic site(s) of action. Brain Res. Bull. 14:521-524.

13. Kalra, P.S., Dube, M.G., Xu, B., and Kalra S.P. 1997. Increased receptor sensitivity to neuropeptide $\mathrm{Y}$ in the hypothalamus may underlie transient hyperphagia and body weight gain. Regul. Pept. 72:121-130.

14. Blomqvist, A.G., and Herzog, H. 1997. Y-receptor subtypes - how many more? Trends. Neurosci. 20:294-298.

15. Gerald, C., et al. 1996. A receptor subtype involved in neuropeptide-Yinduced food intake. Nature. 382:168-171.

16. Lopez-Valpuesta, F.J., Nyce, J.W., and Myers, R.D. 1996. NPY-Y1 receptor antisense injected centrally in rats causes hyperthermia and feeding. Neuroreport. 7:2781-2784.

17. O'Shea, D., et al. 1997. Neuropeptide Y induced feeding in the rat is mediated by a novel receptor. Endocrinology. 138:196-202.

18. Marsh, D.J., Hollopeter, G., Kafer, K.E., and Palmiter, R.D. 1998. Role of the Y5 neuropeptide Y receptor in feeding and obesity. Nat. Med. 4:718-721.

19. Pedrazzini, T., et al. 1998. Cardiovascular response, feeding behaviour and locomotor activity in mice lacking the NPY Y1 receptor. Nat. Med. 4:722-726.

20. Parker, R.M.C., and Herzog, H. 1999. Regional distribution of Y-receptor subtype mRNAs in rat brain. Eur. J. Neurosci. 11:1431-1448.

21. King, B.M. 1988. Glucocorticoids and hypothalamic obesity. Neurosci. Biobehav. Rev. 12:29-37.

22. Rebuffe-Scrive, M., Walsh, U.A., McEwen, B., and Rodin, J. 1992. Effects of chronic stress and exogenous glucocorticoids on regional fat distribution and metabolism. Physiol. Behav. 52: 583-590.

23. Guillaume-Gentil, C., Assimacopoulos-Jeannet, F., and Jeanrenaud, B. 1993. Involvement of non-esterified fatty acid oxidation in glucocorticoid-induced peripheral insulin resistance in vivo in rats. Diabetologia. 36:899-906.

24. Larsen, P.J., Jessop, D.S., Chowdrey, H.S., Lightman, S.L., and Mikkelsen, J.D. 1994. Chronic administration of glucocorticoids directly upregulates prepro-neuropeptide $\mathrm{Y}$ and $\mathrm{Y}_{1}$-receptor $\mathrm{mRNA}$ levels in the arcuate nucleus of the rat. J. Neurendocrinol. 6:153-159.

25. Akabayashi, A., et al. 1994. Hypothalamic neuropeptide Y, its gene expression and receptor activity: relation to circulating corticosterone in adrenalectomized rats. Brain Res. 665:201-212.

26. Freedman, M.R., Horwitz, B.A., and Stern, J.S. 1986. Effect of adrenalectomy and glucocorticoid replacement on development of obesity. Am.J.
Physiol. 250:R595-R607.

27. King, B.M., Banta, A.R., Tharel, G.N., Bruce, B.K., and Frohman, L.A. 1983. Hypothalamic hyperinsulinaemia and obesity: role of adrenal glucocorticoids. Am. J. Physiol. 245:E194-E199.

28. Sainsbury, A., Cusin, I., Rohner-Jeanrenaud, F., and Jeanrenaud, B. 1997. Adrenalectomy prevents the obesity syndrome produced by chronic central neuropeptide Y infusion in normal rats. Diabetes. 46:209-214.

29. Fuxe, K., et al. 1985. Mapping of glucocorticoid receptor immunoreactive neurons in the rat tel- and diencephalon using a monoclonal antibody against rat liver glucocorticoid receptor. Endocrinology. 117:1803-1812.

30. Harfstrand, A., et al. 1989 Regional differences in glucocorticoid receptor immunoreactivity among neuropeptide $\mathrm{Y}$ immunoreactive neurons of the rat brain. Acta Physiol. Scand. 135:3-9.

31. Paxinos, G. and Watson, C. 1986. The rat brain in stereotaxic coordinates. 2nd edition. Academic Press Inc. San Diego, California, USA.

32. Cheng, X., et al. 1998. Regulation of expression of neuropeptide Y, Y1 and Y2 receptors in the arcuate nucleus of fasted rats. Brain Res. 792:89-96.

33. Stanley, B.G., Lanthier, D., Chin, A.S., and Leibowitz, S.F. 1989. Suppression of neuropeptide Y-elicited eating by adrenalectomy or hypophysectomy: reversal with corticosterone. Brain Res. 501:32-36.

34. Tempel, D.L., and Leibowitz, S.F. 1993. Glucocorticoid receptors in PVN: interactions with NE, NPY, and Gal in relation to feeding. Am. J. Physiol. 265:E794-E800.

35. Kalra, S.P., Dube, M.G. and Kalra, P.S. 1988. Continuous intraventricular infusion of neuropeptide Y evokes episodic food intake in satiated female rats: effects of adrenalectomy and cholecystokinin. Peptides. 9:723-728.

36. Morley, J.E., Levine, A.S., Gosnell, B.A., Kneip, J., and Grace, M. 1987. Effect of neuropeptide Y on ingestive behaviors in the rat. Am. J. Physiol. 252:R599-609.

37. Dallman, M.F. 1984. Viewing the ventromedial hypothalamus from the adrenal gland. Am. J. Physiol. 246:R1-R12.

38. Ball, H.J., Shine, J., and Herzog, H. 1995. Multiple promoters regulate tissue-specific expression of the human NPY Y1 receptor gene. J. Biol. Chem. 270:27272-27276.

39. Statnick, M.A., et al. 1998. Characterization of the neuropeptide Y5 receptor in the human hypothalamus: a lack of correlation between Y5 mRNA levels and binding sites. Brain Res. 810:16-26.

40. Zakrzewska, K.E., et al. 1999. Induction of obesity and hyperleptinemia by central glucocorticoid infusion in the rat. Diabetes. 48:365-370.

41. Arase, K., Shargill, N.S., and Bray, G. 1989. Effects of intracerebroventricular infusion of corticotrophin-releasing factor on VMH-lesioned obese rats. Am. J. Physiol. 256:R751-R756.

42. Rohner-Jeanrenaud, F., Walker, C.D., Greco-Perotto, R., and Jeanrenaud, B. 1989. Central corticotropin releasing factor administration prevents the excessive body weight gain of genetically obese $(f a / f a)$ rats. Endocrinology. 124:733-739.

43. Bchini-Hooft van Huijsduijnen, O.B., Rohner-Jeanrenaud, F., and Jeanrenaud, B. 1993. Hypothalamic neuropeptide Y messenger ribonucleic acid levels in pre-obese and genetically obese $(f a / f a)$ rats; potential regulation thereof by corticotrophin-releasing factor. J. Neuroendocrinol. 5:381-386.

44. Makino, S., Nishiyama, M., Asaba, K., Gold, P.W., and Hashimoto, K. 1998. Altered expression of type $2 \mathrm{CRH}$ receptor mRNA in the VMH by glucocorticoids and starvation. Am. J. Physiol. 275:R1138-R1145.

45. Guan, X.M., et al. 1998. Induction of neuropeptide Y expression in dorsomedial hypothalamus of diet-induced obese mice. Neuroreport. 9:3415-3419.

46. Heidel, E., Plagemann, A., and Davidowa, H. 1999. Increased response to NPY of hypothalamic VMH neurons in postnatally overfed juvenile rats. Neuroreport. 10:1827-1831.

47. Leibowitz, S.F., Sladek, C., Spencer, L., and Tempel, D. 1988. Neuropeptide $Y$, epinephrine and norepinephrine in the paraventricular nucleus: stimulation of feeding and the release of corticosterone, vasopressin and glucose. Brain Res. Bull. 21:905-912. 